\title{
DISCUSSION - SESSION VI
}

Principal discussants: Gordon Pearson, Queen's University of Belfast, Michael Kessler, Canberra Packard, Doug Harkness, NERC, Murdoch Baxter, SURRC

Considerable discussion focused on current liquid scintillation technology, and some dissatisfaction with information channels between manufacturer and user was expressed. A proposal followed to form a group of experts in the ${ }^{14} \mathrm{C}$ community and the manufacturers to provide assistance to labs.

\section{CONCLUDING SESSION (see Summary by M S Baxter)}

Professor Baxter summarized the achievements of the meeting in terms of present findings and future implications of the current study, particularly regarding the agreements on international quality control and assurance.

\section{For the Present}

- Variability in the results increased from stage to stage, but we observed the major variability in Stages 2 and 3, which involved more realistic samples.

- Lab biases still exist, so that the results are similar to the previous Glasgow coordinated study.

- Some differences between techniques are apparent; LS results seem more varied generally but AMS seem more varied for the more modern samples.

- Quoted errors do not quantitatively describe the observed variability.

- Only 7 labs out of 38 appeared to pass the three performance criteria which had been defined.

- For GPC and LSC $\sim 2 / 3$ of external variation derives from counting and synthesis processes, for AMS $\sim 2 / 3$ of external variation seems associated with sampling from realistic samples and their pretreatment.

- It was encouraging that the study had already proven useful to individual labs.

- The group enthusiastically endorsed continuation of the collaborative program and generally accepted proposals already presented.

\section{For the Future}

Quality Assurance is basically putting into operation the principles of good laboratory practice, but it is still a matter of individual responsibility. With this in mind, the major initiative of the IAEA should be welcomed. It should also improve international help and cooperation.

The UK National Environment Research Council (NERC) and the Science and Engineering Research Council (SERC) will fund further blind inter-comparisons and invite laboratories to participate. The Glasgow/East Kilbride group will coordinate the studies. The proposed schedule follows:

1. Austin Long will draft and collate the recommended QA procedures.

2. IAEA will provide samples of modern cellulose, charcoal, marine sediment and modern travertine marble - to be distributed in February ${ }^{1}$ 1990. Results should go to Vienna by July ${ }^{1}$ and be discussed at the meeting in October. ${ }^{1}$ 
3. Labs should follow QA procedures involving regular assay of IAEA reference materials as well as in-house standards.

4. A further intercomparison will be organized by Glasgow/EK group and will be free of charge; suitable sample material collected in 1990 and a commitment to participate will be sought after the Vienna meeting. This study will begin in 1991/92.

The meeting closed on optimistic notes for the future. 